\title{
Caring for older people with dementia reliving past trauma
}

\section{Åsa Gransjön Craftman (1) \\ Department of Nursing Science, Sophiahemmet University, Sweden}

\author{
Anna Swall \\ Dalarna University, Sweden
}

\section{Kajsa Båkman}

Föreningen Judiska Hemmet, Sweden

\author{
Åke Grundberg \\ Department of Nursing Science, Sophiahemmet University, Sweden
}

\section{Carina Lundh Hagelin (1)}

Department of Caring, Science and Karolinska Institutet; Department of Neurobiology, Caring Sciences and Society, Ersta Sköndal Bräcke University College, Sweden

\begin{abstract}
Background: The occurrence of behavioural changes and problems, and degree of paranoid thoughts, are significantly higher among people who have experienced extreme trauma such as during the Holocaust. People with dementia and traumatic past experiences may have flashbacks reminding them of these experiences, which is of relevance in caring situations. In nursing homes for people with dementia, nursing assistants are often the group of staff who provide help with personal needs. They have firsthand experience of care and managing the devastating outcomes of inadequate understanding of a person's past experiences.

Aim: The aim was to describe nursing assistants' experiences of caring for older people with dementia who have experienced Holocaust trauma.

Research design: A qualitative descriptive and inductive approach was used, including qualitative interviews and content analysis.

Participants and research context: Nine nursing assistants from a Jewish nursing home were interviewed. Ethical considerations: The study was approved by the Regional Ethical Review Board, Stockholm.

Findings: The theme 'Adapting and following the survivors' expression of their situation' was built on two categories: Knowing the life story enables adjustments in the care and Need for flexibility in managing emotional expressions.

Discussion and conclusion: The world still witnesses genocidal violence and such traumatic experiences will therefore be reflected in different ways when caring for survivors with dementia in the future. Personcentred care and an awareness of the meaning of being a survivor of severe trauma make it possible to avoid negative triggers, and confirm emotions and comfort people during negative flashbacks in caring situations and environments. Nursing assistants' patience and empathy were supported by a wider understanding of the behaviour of people with dementia who have survived trauma.
\end{abstract}

Corresponding author: Åsa Gransjön Craftman, Department of Nursing Science, Sophiahemmet University, Box 5605 , SE- I I 486 Stockholm, Sweden.

Email: asa.craftman@shh.se 


\section{Keywords}

Dementia, nursing home, professional caregivers, survivors, trauma

\section{Introduction}

People who have been exposed to trauma in early life may experience age-related decline considerably earlier, and to a greater extent, compared to their non-traumatised counterparts. ${ }^{1}$ A person who experienced the Holocaust during World War II (WW II) is described as a survivor, which represents the severe mental trauma that the person lived through in early life. ${ }^{2}$ The research focus concerning Holocaust survivors has shifted from investigating this cohort's symptoms of post-traumatic stress disorder (PTSD) to discovering the sources of strength and resilience, and exploring the perspectives of second- and third-generation survivors. ${ }^{3,4}$ Earlier literature concerning ageing Holocaust survivors initially focused on camp survivors who had experience of receiving psychiatric treatment ${ }^{5,6}$ and found that they were more predisposed to mental health problems since they had to deal with age-related life transitions and struggle with continuous post-traumatic memories from the Holocaust. ${ }^{2,7-11}$ It has also been described that individuals who have been exposed to massive trauma suffer from greater physical ${ }^{12,13}$ and psychological morbidity. ${ }^{14,15}$ The symptoms experienced by those who suffer from PTSD are often similar, although each individual's experiences are unique. However, people who have experienced mental trauma often have a common sense of loss and pain. ${ }^{16}$ The ability to integrate past trauma and present challenges within a unified self is intertwined with the survivor's time perspective. This enmeshment of traumatic experiences from the past into psychological functioning in the present is described as Holocaust-as-present. ${ }^{17}$

Dementia is an overarching term for several neurodegenerative diseases that most often affect older people and have a chronic and progressive nature. ${ }^{18}$ Changes in behaviour, as well as cognitive decline and personality changes, are noted when the disease progresses, ${ }^{19}$ as are changes such as loss of empathy, inappropriate behaviour and loss of judgement. ${ }^{20} \mathrm{~A}$ person with dementia (PWD) may still have their rehearsed memories (implicit memory) but might have difficulty talking about them (explicit memory). The implicit memory could instead be expressed in behaviours such as crying and sadness. The emotion is present but the person may not understand the expression of it. ${ }^{21}$ Healthcare professionals may often misinterpret agitation in people with dementia and therefore not understand that this behaviour is due to the way the individual is experiencing their reality. ${ }^{22}$ Based on Kitwood's ${ }^{23}$ initial work on person-centred care (PCC), this approach has been further developed and conceptualised at a theoretical level ${ }^{24}$ and, over the past 10 years, in descriptions and tools for PCC in dementia care. The importance of knowing about a person's life history has been emphasised since this allows the person's identity to be maintained. ${ }^{25,26}$ According to Graneheim et al., ${ }^{27}$ the care of a PWD should be facilitated by the awareness that emotional memories can last longer than cognitive memory. This means that a positive experience can be forgotten due to a reduced short-term memory; however, the positive feeling may last longer, which means that adequate PCC can be effective for longer than just for the moment.

Nurses and other staff working in older people care often describe caring for older survivors as 'difficult' and reveal that it is vital to develop an understanding of and empathy with the individual's earlier trauma. ${ }^{28-30}$ Moreover, the occurrence of behavioural and mental problems, and degree of paranoid thoughts, are significantly higher among those who have experienced what is considered to be 'extreme trauma', such as that occurring during the Holocaust. ${ }^{31}$ During the early 2000 s, research in this area focused less on the negative psychological effects and more on vulnerability and resilience, such as the long-term effects of early trauma, ${ }^{32}$ good instrumental coping and preserved functioning despite PTSD,${ }^{33}$ and meaning-finding and successful ageing in post-traumatic living. ${ }^{34}$ Research also focused on Holocaust survivors' perceptions of ageing and experiences of residential care. ${ }^{35,36}$ 
The world still witnesses genocidal violence ${ }^{37}$ causing PTSD, which will be reflected in the care of the older people and PWDs in the future. Knowledge therefore needs to be obtained about the care of persons who have experienced trauma and have been wilfully victimised by others. David ${ }^{16}$ writes that, since people are living longer, for the first time in history, through the group of Holocaust survivors, we can see the consequences that severe trauma in previous years has for the nursing care of these people when they get older. Even though earlier literature has focused on clinicians' experiences of caring for Holocaust survivors in nursing homes, ${ }^{29}$ geriatric care, ${ }^{38}$ hospitals ${ }^{28,39,40}$ or in hospice and palliative care, ${ }^{41}$ limited research has been conducted on the healthcare professional's perspective when it comes to PCC for Holocaust survivors with dementia in their daily life when in long-term care.

\section{Aim}

The aim was to describe nursing assistants' (NAs) experiences of caring for older people with dementia who have experienced Holocaust trauma.

\section{Method}

\section{Study design, participants and setting}

The members of the research group have both research and clinical experience of older people care and dementia care, and two members (K.B., A.G.) have clinical experience of caring for older PWDs known to have experienced trauma. A qualitative descriptive and inductive approach was used to describe NAs' experiences of caring for PWDs who experienced the Holocaust. The manager of a designated nursing home in Sweden, where about $70 \%$ of the residents were survivors of the Holocaust during WWII, was contacted and approved the request to recruit participants. Inclusion criteria were working as a NA involved in direct patient care, with at least 2 years of practical experience of caring for older PWDs who had experienced the Holocaust. Information about the study, both written and verbal, was presented to the day-time staff at a regular staff meeting and to the night-time staff through personal e-mail. The participants who accepted the invitation were given the opportunity to choose both time and place for the interviews. NAs volunteered and signed an informed consent before the interview started. Individual interviews were conducted with nine participants $(n=9)$; six females and three males aged 28-57 years (mean 53) with working experience of 3-14 years (mean 10). All NAs had a 3-year upper secondary education from a Health Care Programme, including theoretical studies and practical training. Eight NAs worked day shifts and one night shifts.

\section{Data collection}

A semi-structured study-specific interview guide (see Table 1) was developed by the research group and scrutinised by a specialist nurse in dementia care with long experience of caring for older survivors. The second author of this study conducted all the interviews, including two pilot interviews that gave rich data and which, since no changes were made, were included in the analysis. The interviews were conducted during the NAs' regular working hours and a maximum of $1 \mathrm{~h}$ was allocated for each interview. The interview with the night staff was conducted $1 \mathrm{~h}$ before the night shift began. The interviews lasted between 20 and 50 (mean 39) min and were digitally recorded with permission from the participants. The recorded interviews were transcribed verbatim. After nine interviews, data saturation or 'informational redundancy' as described by Sandelowski and Given ${ }^{42}$ was considered to have been achieved, that is, no more variation of data appeared. 
Table I. The Interview guide.

Could you please tell me about your experiences in general of caring for people who survived World War II and suffer from dementia?

What do you consider to be important to keep in mind when caring for people with dementia who have experienced this kind of trauma?

Have you experienced a situation where you identified that the person with dementia was reliving a difficult memory from the past?

If yes;

How did you handle the situation?

How do you think one can avoid triggering the memories of people who survived the Holocaust or experienced similar trauma?

\section{Data analysis}

Collected data were analysed using qualitative content analysis with a manifest and latent approach ${ }^{43}$; the steps during the analysis process were inspired by Graneheim and Lundman. ${ }^{44}$ All recorded interviews were transcribed verbatim and the text was double-checked in order to confirm that no words had been omitted. The analysis was performed by the author K.B. in collaboration with authors A.G.C. and C.L.H. First, the text was read repeatedly to capture and identify its content. Subsequently, meaning units based on the aim of the study were identified and marked with a code according to their manifest content. The codes were then compared based on similarities and differences and further sorted into subcategories according to their similarities. The subcategories were then compared for similarities and abstracted into categories. A category refers often to a descriptive level of content and may answer the question 'What?'44 One overarching theme was then formulated. A theme can be seen as an expression of the latent content of the data and answers the question 'How?' ${ }^{44}$ To enhance trustworthiness, all steps in the analysis process were reflected on and discussed by the research team throughout the whole process, resulting in consolidation of the findings (Table 2).

Table 2. Subcategories, Categories and Theme.

\begin{tabular}{lll}
\hline Subcategory & Category & Theme \\
\hline $\begin{array}{c}\text { The significance of person-centred } \\
\text { care }\end{array}$ & $\begin{array}{c}\text { Knowing the life story enables } \\
\text { adjustments in the care }\end{array}$ & $\begin{array}{c}\text { Adapting and following the survivors' } \\
\text { expression of their situation }\end{array}$ \\
$\begin{array}{c}\text { Knowing the person's life story } \\
\text { Having to deal with challenging } \\
\text { situations }\end{array}$ & $\begin{array}{c}\text { Need for flexibility in managing } \\
\text { emotional expressions }\end{array}$ \\
$\begin{array}{l}\text { Avoiding and adjusting to potential } \\
\text { triggers }\end{array}$ & $\begin{array}{l} \\
\end{array}$
\end{tabular}

\section{Ethical considerations}

Ethical consideration was carefully made according to the Declaration of Helsinki and approved by the Regional Ethical Review Board in Stockholm, Sweden (EPN 2013/28-31). All participants received information about the study explaining the voluntary nature and confidentiality of participation and that they could withdraw their participation at any time. The interviews were coded with numbers to maintain confidentiality and kept secure so that only the research group had access to the material. To ensure participant confidentiality, only gender aspects and working experience are presented. 


\section{Findings}

The overarching theme was Adapting and following the survivors' expression of their situation. This theme was built on two categories: Knowing the life story enables adjustments in the care and Need for flexibility in managing emotional expressions, and four subcategories.

According to the NAs, caring for older PWDs who experienced the Holocaust meant adapting and, through acting, relieving the trauma by presence, following the PWDs' expressions of their situation. This was based on the foundation of understanding how their traumatic life story could affect the individual person in caring situations and in their environment. Caring for these people was dependent on a trusting relationship and an environment where the person was protected from triggers in daily life. Furthermore, the awareness of and need for flexibility in challenging situations and emotional expressions was described as trying to promote the person's need for their own engagement, autonomy and participation in the caring situation. The everyday life on the ward was mirrored by the person's memories from the past, which led the NAs to adopt PCC in order to maintain the 'me' and the 'self' of the person.

Knowing the life story enables adjustments in the care. Each person's unique life story provides an essential basis for care and PCC was therefore even more essential, according to the informants. The person's life story provided the possibility to adjust the care and also be wary of specific triggers. Moreover, the team, consisting of all professions involved in the care, had the possibility to discuss and inform about specific triggers. This was important to share with all the staff since the triggers could start situations that could be emotional demanding for both the PWD and the staff.

The significance of PCC was emphasised in the interviews as was the importance of interprofessional teamwork. The team was described as consisting of NAs, registered nurses and a physician. Problems and challenges that were raised concerning the care of a person were resolved and reflected on in the team. The NAs stressed that it was important that the team members worked towards the same goals regarding the care. Furthermore, team members shared tips in order to be able to develop the best care for the individual in a person-centred way, depending on each person's situation. According to the NAs, the team members supported each other in the provision of the best possible care in demanding care situations, including challenging behaviour by PWDs such as screaming, aggression and being hostile, to enable PCC. However, despite the good teamwork involving person-centredness, it could be emotionally demanding caring for PWDs, especially when they lose their verbal ability:

There are similarities (between survivors with and without dementia), but it worsens when they (survivors) become demented, clearly... Everyone has their memories, but when you have dementia, you cannot sort out what is what (a memory recall or an episode in the present time)...

Both humour and songs were mentioned by the NAs as effective methods of diversion, when needed. The NAs explained how they tried to understand the person's interpretation of the present context. Similarly, the NAs described the importance of working in teams with common goals for the care of each individual, so that knowledge about how the person is best cared for was communicated to all staff. This was deemed important in particular situations.

... we were drinking the shabat-coffee as we usually do and I had to turn away from the woman next to me. Suddenly she became very angry and screamed that I was rude and should not be there. She saw me as a prison 
guard from the past and asked another NA to tell me to go, and burst into tears. I knew this could happen, but I have never experienced it as strongly as then. I left to let the woman calm down. (I.9)

This kind of situation was interpreted by the NAs as the person's terrible memories connected with their experiences of WWII, possibly of a female prison guard. In similar situations, the NAs tried to diffuse the situation, for example, by leaving the room for a while to let the person calm down.

Knowing the person's life story was, according to the NAs, important for providing the best possible care. However, asking the persons about their past was strictly avoided out of respect for their integrity and to avoid triggers. Help from the next of kin was often needed to gain information about the PWD's life story, but several of the NAs stated that the relatives frequently did not know much about the PWD's past. This was considered as being due to the emotional difficulties the PWD had in communicating the horror they had been through.

They (the children of the survivors) do not know much about their relatives. We had a lady here, but she has passed away now, but her daughter said that her mother's life began when she married and had children in Sweden (after the WWII). She knew some things, but it was so hard for her mother to tell her that they never knew what she had been through. (I.4)

Newly recruited NAs were encouraged to read the person's life story and, if they had questions, ask other NAs rather than asking the older person about their background. According to the NAs, it was, however, important to be aware and take into account that the person could suddenly be reminded about their traumatic past. It was easier for the NAs to meet the sometimes unexpected emotions in care situations, such as wishes to withdraw and be left alone, rather than anger, anxiety and sorrow.

\section{Need for flexibility in managing emotional expressions}

Emotional expressions by PWDs which were related to or had elements of traumatic memories could appear. Reactions to triggers could arise unintentionally and a colleague needed to take over when the NA was unable to carry out what they perceived to be challenging in such situations. The PWD's short-term memory was used to divert a harsh thought in order to calm the person. However, the NAs experienced that the person's difficult feelings needed to be confirmed.

Having to deal with challenging situations was described by the NAs, for example, when helping the person with their personal hygiene. The PWD could have memories of being forced to undress and shower in the concentration camp, which induced traumatic reactions, including hitting and kicking, that were difficult to manage. Showering was particularly challenging for a PWD and was regarded as a most delicate caring situation for both the NAs and, not least, the WWII PWDs. Being patient, talking and acting calmly, and including the person in the process, were important practices when assisting a PWD in the shower. Keeping calm and working 'step by step' was also said to reduce the risk.

You had to try to do as well as you could; it was not easy to avoid the battles. Sometimes it was better; it was a bit up and down. It was mostly when you helped her with her personal hygiene or dressing. (I.1)

The NAs described how important it was to spend time building up a positive relationship and gaining the confidence of a survivor with dementia. Giving information about plans to shower could start by offering the person something they like, such as a cup of coffee, as a strategy to relieve anxiety. An example of how triggers could be handled was illustrated by the way a shower was performed; you must start showering from the feet and up to the shoulders, avoiding the head and the hair. It was important to be in front of the person, have eye contact, communicate what is going to happen and generate trust. Last of all, the hair was 
washed; alternatively, this was done on another occasion or at the hairdresser. This way, the person experienced the situation as less threatening and uncomfortable, and the NAs found themselves being supportive. NAs also found conversation and physical contact, for example, tactile massage, useful in reducing worry. This was also valuable at bedtime and in the night if the person had problems sleeping due to stressful and upsetting thoughts. The NAs described how it was sometimes necessary to tell 'white lies' and follow the situation which could mean playing an active role. The purpose was to calm the person's worries since they could become more upset if the NA tried to correct them and tell the truth.

We have a woman who often wakes up during the night crying for the hungry children ... Yes, I said to her, I have fruit and I will give them to the children and then I stamped my feet and said '- listen, now they have stopped crying, they've eaten a lot' - 'Thank you dear Lord!' She said. (I.5)

Most NAs had previously worked in nursing homes with older PWDs and compared these experiences with how they perceived working with survivors with dementia. They described that PWDs have a greater degree of anxiety and are more sensitive to stress. It was also perceived that older persons who have experienced trauma could be more suspicious and needed to feel that they had control. It was more difficult dealing with feelings and memories that may appear due to trauma if the person also had dementia. The NAs stated that not everyone could deal with the demands of caring for PWDs and some left their jobs.

However, it was considered to be an honour to give good care to these people and was also regarded as rewarding and educational work.

You work a lot with your mind. They have so much anxiety, screaming he will murder me, he will murder me. Do you know who he is? My mother, they will kill my mother, my father has been killed. (I.2)

Food was a major, recurring subject. Clearing the table was a challenging situation when the PWDs were present. Their concern about not knowing if and when food would be served next was a big issue and they repeatedly asked for food. NAs were not allowed to take a woman's plate away with her untouched lunch, she said that it was her food and was not to be moved. Bread seemed to have a symbolic value of comfort and was used for that purpose.

... several of the elderly may have a sandwich in their room at night, even if they do not eat it, just to know that there is food available...

We offer him sandwiches, or something (edible) to put on his walking frame. Then he becomes calm and he takes his walking frame into the room. Sometimes the sandwich is still there in the morning, but he is calm if he has a sandwich. (I.8)

NAs could also find food hidden in the room, in the bed and in clothes. They avoided throwing food away since this caused the person great concern if they saw this happening, even if it was spoiled. In some cases, old food was replaced with new or thrown away secretly.

Avoiding and adjusting to potential triggers was described as central by the NAs. It was seen as important to avoid and manage known triggers and agitating memories. Potential triggers were clothing, for example, high boots, but also dramatic news on the TV or radio, and being among a large group of people seemed to recall memories from the past. The NAs tried to calm the PWD in such situations.

The Nazis are coming to kill everyone!... it's like she experiences the same thing again and again. Then, she would walk around and scream. Then you have to try as much as you can to calm her and say: It's not true, they are not here, the Nazis went a long time ago. (I.1) 
The NAs described how they could see and perceive a mood, and also a relationship with and orientation to time and the PWD's environment. One description was of how a man refused to take his clothes off and always slept with his shoes on in order to be ready to flee. The same man had a desire for food, more explicitly bananas. This was something that the NAs used to adjust for triggers; providing him with bananas seemed to give him a feeling of comfort and security. He could then accept assistance in care situations, which included helping him change his clothes and assisting with personal hygiene.

The PWDs' relationship to the environment was also crucial; being in open spaces and surrounded by people could be stressful and a reminder of time in the camp, and some PWDs preferred to be alone in their room. Being in small and confined spaces, such as the toilet or the bathroom, could also be stressful if they felt unable to exit. One NA described the following:

I think her memories come back from when she has been hidden as girl in a small utility room in an apartment and could never go out. (I.4)

All NAs were given a comprehensive introduction on avoiding triggers. The NAs described how the PWDs were easily scared, and therefore you should, for example, ensure that you announce your presence when entering a PWD's room or when touching them. You should also avoid moments of surprise, since these triggered emotions such as fear and aggression.

\section{Discussion}

Our findings revealed the theme Adapting and following the survivors' expression of their situation, illuminating the aim of the study. NAs should have an awareness of and take into account how progressive dementia develops and how it can lead to PWDs, who have not previously talked about their past, revealing their traumatic experiences. It may be a painful experience for the PWDs who are influenced by difficulties in orienting in time, place and emotions. NAs described how they worked with a person-centred focus by acting and giving care in relation to the given situation and the emotions expressed by the person. Kitwood's 23 framework for PCC could be seen as being in line with the PCC delivered by the NAs who strive to deliver optimum care for older PWDs in order to support the PWDs' personhood in challenging situations. According to Kitwood, ${ }^{45}$ the PWDs have a hidden personhood not a lost one, which occasionally mirrors the life world that the person is currently experiencing. The personhood of the PWDs may also have been shaped by their life during WWII, which could in turn mirror the caring situation. The attributes of NAs, the physical and emotional context, and the environment in the nursing home are also central components of this care. However, high staff turnover was described due to emotional exhaustion. Based on the results in the present study, the organisational culture must ensure that the organisation's policies, values and approach support NAs in the PCC of older PWDs, especially those who have experienced a trauma. For example, this could be with education about the PWD's specific trauma event for staff to enable them to adapt and follow the individual in their memories.

Our findings showed how the NAs had to adapt and include the relatives when this occurred, in line with the PWD's overall situation and as part of the care. The effects of the dementia process on memory could reveal well-hidden trauma, which could also be very emotional for relatives who were confronted with sometimes severe existential pain. McCormack et al. ${ }^{46}$ has described how the dementia process can be a distressing experience for next of kin even without the presence of a traumatic background. Feelings of grief, loss and guilt are described as being like 'closing a window'. However, Scharf and Mayseless ${ }^{47}$ and Samson et al. ${ }^{48}$ described how transmission of trauma to second- and third-generation Holocaust survivors and survivors of other traumas may occur. Narratives regarding the traumatic experiences could be 
transferred from one generation to the next. The second-generation Holocaust survivors might have the challenging role of shielding their parents from experiencing further pain.

Being dependent on others for their daily living can be perceived as demanding for survivors. The strong feeling of trusting only yourself after having survived trauma has also been described by Teshuva et al. ${ }^{49}$ and Teshuva and Wells. ${ }^{50}$ The lack of the cognitive-emotional ability to integrate past experiences into current life circumstances is also considered ${ }^{51}$ to be even more challenging, since the post-traumatic stress of Holocaust survivors resides long in their past. One explanation could be that what a person experiences as a safe and known environment suddenly becomes extremely threatening and hostile without rational explanation or, for the NAs, apparent meaning; the occurrence of such a situation is therefore unpredictable. The NAs meet both the person emerging from their hidden past and, in this case, the person's progressing dementia, which hinders the PWD from being able to ward off emotions and traumatic memories. The traumatic experiences recur in the present just as strongly, and are relived as fully, as in the past. These negative emotional expressions, which could include being aggressive, were challenging for NAs to handle when they occurred. ${ }^{28,30,52}$ In many situations in the care of a PWD, these memory-triggers (Reminiscence) are seen as a very important tool to connect with the PWD through life memories. ${ }^{53}$ Several studies suggest that alternative methods, for example, a therapy $\mathrm{dog},{ }^{54}$ tactile stimulation, ${ }^{55}$ caregivers singing, ${ }^{56}$ and therapeutic and person-centred conversations, ${ }^{57}$ are ways to reach reminiscence and person-centredness. In the present study, the NAs needed to adapt and use their skills regarding PCC in situations to avoid triggers, which is very demanding. The everyday life on the ward was mirrored by the person's memories from the past. The NAs described how some survivors simply ignored their lives during WWII before they came to Sweden and started a new life. This resulted in their children maybe only knowing some of their parent's experiences during WWII, as some things were left unspoken. Our findings showed how the emotional demands on the NAs were discussed within the interprofessional team. It was valuable to discuss and inform about particular situations, such as when a NA was suddenly perceived as being a guard from the camp by a PWD who became very upset.

Previous research stresses that food is a sensitive and crucial factor, where bread has a poignant power for survivors. ${ }^{36,58,59}$ Removal of spoiled food, or food not being readily available, was associated with anxiety, whereas excess food eased the stress. This was also described by the NAs as one example of prominent actions connected to life in the camp. NAs in the study experienced and perceived food as having a complex implication, symbolising both comfort and anxiety, and being a memory trigger. The NAs were aware that they should not clear the table if this was sensitive for a PWD. To mediate relief and empowerment, the participating NAs in our study were eager to let the PWDs have bread or fruit in sight and within reach, for example, stuffed in a pocket or on their walking frame. NAs endorsed the comforting purpose that the PWDs seemed to perceive when being able to provide food for themselves. In addition, old food was removed, or replaced due to health risks, gently and out of sight of the PWD.

\section{Limitations, transferability and credibility}

The limitations and strengths of this study have been highlighted using Lincoln and Guba. ${ }^{60}$ The authors' preunderstanding could be seen as both a strength and a limitation. However, the knowledge within the research group made it possible to approach the area, formulate questions, and analyse and understand the data. To avoid interpretations based on the researchers' own values, the content of data and what was actually expressed was constantly discussed with an open mind and the expectation of finding new perspectives. The sample included can be seen as small, although important due to its uniqueness, and transferability can be considered possible to nursing homes caring for PWDs who have survived severe trauma, where triggers lead to reliving the trauma. To reach credibility, each step of the analysis process was characterised by flexibility and repetitive verification of the original text, and through being 
discussed within the research group. Any discrepancies were examined until consensus was reached. Two of the authors (A.S., A.G.) confirmed the initial analysis, checking interpretation to confirm the trustworthiness of the findings by reviewing the process from raw data through to interpretation. The final analysis was performed in collaboration with the entire group to avoid preunderstanding unintentionally influencing the interpretation. The relationship between the findings and international nursing ethics is outlined in the importance of balancing the need of person centered care based on traumatic experiences from the past.

\section{Conclusion}

This study supports previous research on the challenge of caring for PWDs who have experienced trauma and how NAs need to adapt the care. In addition, the study contributes with clear knowledge of how care needs to follow the individual and that care needs to be based on both in-depth, contemporary knowledge of the trauma (here WWII) and the individual's life story. This is a way for NAs to enable essential PCC and to successfully interact with a PWD during caring situations. NAs' knowledge of the historical context of when the trauma occurred seems to be crucial. This provides them with the ability to confirm the feelings of and comfort the PWD in emotionally challenging situations when trauma from the past becomes entangled in the present, in the presence of dementia.

\section{Acknowledgements}

Thank you to all participants who kindly gave us their time and shared their valuable experiences.

\section{Author contributions}

Study design was performed by K.B. and C.L.H; data collection by K.B; data analysis by K.B., C.L.H., Å.G.C., A.S. and A.G; and manuscript preparation by Å.G.C., A.S., Å.G., K.B. and C.L.H.

\section{Conflict of interest}

The author(s) declared no potential conflicts of interest with respect to the research, authorship and/or publication of this article.

\section{Ethical approval}

This study was approved by the Regional Ethical Review Board in Stockholm, Sweden (EPN 2013/28-31).

\section{Funding}

The author(s) disclosed receipt of the following financial support for the research, authorship and/or publication of this article: This article was financially supported by Drottning Silvias Stiftelse för Forskning och Utbildning [Queen Silvia's Foundation for Research and Education].

\section{ORCID iD}

Åsa Gransjön Craftman (D https://orcid.org/0000-0002-0553-199X

Carina Lundh Hagelin (D) https://orcid.org/0000-0002-0197-9121

\section{References}

1. Lapp LK, Agbokou C and Ferreri F. PTSD in the elderly: the interaction between trauma and aging. Int Psychogeriatr 2011; 23(6): 858-868.

2. Sadavoy J. Survivors: a review of the late-life effects of prior psychological trauma. Am J Geriatr Psychiatry 1997; 5(4): 287-301. 
3. Cohenca-Shiby D and Aviad-Wilchek Y. The effects of gender and survival situation of the parent Holocaust survivor on their offspring: an attachment perspective. Isr J Psychiatry Relat Sci 2018; 55(2): 15-20.

4. Cohn I and Morrisson N. Echoes of transgenerational trauma in the lived experiences of Jewish Australian grandchildren of Holocaust survivors: transgenerational trauma - the third generation. Austr J Psychol 2017; 70(5): 199-207.

5. Kellermann N. Holocaust trauma: psychological effects and treatment. Bloomington, IN: iUniverse, 2010.

6. Niederland WG. The survivor syndrome: further observations and dimensions. J Am Psychoanal Assoc 1981; 29(2): 413-425.

7. Amir M and Lev-Wiesel R. Time does not heal all wounds: quality of life and psychological distress of people who survived the Holocaust as children 55 years later. J Trauma Stress 2003; 16(3): 295-299.

8. Brodaty H, Joffe C, Luscombe G, et al. Vulnerability to post-traumatic stress disorder and psychological morbidity in aged Holocaust survivors. Int J Geriatr Psychiatry 2004; 19(10): 968-979.

9. Danieli Y. As survivors age: an overview. J Geriatr Psychiatry 1997; 1(9): 9-26.

10. Trappler B, Braunstein JW, Moskowitz G, et al. Holocaust survivors in a primary care setting: fifty years later. Psychol Rep 2002; 91(2): 545-552.

11. Herman J. Trauma and recovery: the aftermath of violence from domestic abuse to political terror. New York: Basic Books, 1997.

12. Iecovich $\mathrm{E}$ and Carmel S. Health and functional status and utilization of health care services among Holocaust survivors and their counterparts in Israel. Arch Gerontol Geriatr 2010; 51(3): 304-308.

13. Keinan-Boker L, Vin-Raviv N, Liphshitz I, et al. Cancer incidence in Israeli Jewish survivors of World War II. J Natl Cancer Inst 2009; 101(21): 1489-1500.

14. Steel Z, Chey T, Silove D, et al. Association of torture and other potentially traumatic events with mental health outcomes among populations exposed to mass conflict and displacement: a systematic review and meta-analysis. JAMA 2009; 302(5): 537-549.

15. Barel E, Van IJzendoorn MH, Sagi-Schwartz A, et al. Surviving the Holocaust: a meta-analysis of the long-term sequelae of a genocide. Psychol Bull 2010; 136(5): 677-698.

16. David P. War survivors and dementia: one more battle to fight. Can Nurs Home 2005; 16(1): 12-18.

17. Shmotkin D and Barilan YM. Expressions of Holocaust experience and their relationship to mental symptoms and physical morbidity among Holocaust survivor patients. J Behav Med 2002; 25(2): 115-134.

18. World Health Organization. Dementia, 2012, https:/www.who.int/news-room/fact-sheets/detail/dementia

19. Halloran L. Behavioral and psychological symptoms of dementia. J Nurse Pract 2014; 10(8): 625-626.

20. Hugo J and Ganguli M. Dementia and cognitive impairment: epidemiology, diagnosis, and treatment. Clin Geriatr Med 2014; 30(3): 421-442.

21. Sabat SR. Implicit memory and people with Alzheimer's disease: implication for caregiving. Am J Alzheimer's Dis Other Demen 2006; 21(1): 11-14.

22. Volicer L and Hurley AC. Management of behavioral symptoms in progressive degenerative dementias. J Gerontol A Biol Sci Med Sci 2003; 58(9): M837-M845.

23. Kitwood T. Towards a theory of dementia care: the interpersonal process. Age Society 1993; 13: 51-67.

24. McCormack B. Person-centredness in gerontological nursing: an overview of the literature. J Clin Nurs 2004; 13(3a): 31-38.

25. McKinney A. The value of life story work for staff, people with dementia and family members. Nurs Older People 2017; 29(5): 25-29.

26. McKeown J, Ryan T, Ingleton C, et al. 'You have to be mindful of whose story it is': the challenges of undertaking life story work with people with dementia and their family carers. Dementia (London) 2015; 14(2): $238-256$.

27. Graneheim UH, Isaksson U, Ljung IM, et al. Balancing between contradictions: the meaning of interaction with people suffering from dementia and 'behavioral disturbances'. Int J Aging Hum Dev 2005; 60(2): 145-157. 
28. Ehrlich MA.Health professionals, Jewish religion and community structure in the service of the aging Holocaust survivor. Arch Gerontol Geriatr 2004; 38(3): 289-295.

29. Adams KB, Mann ES, Prigal RW, et al. Holocaust survivors in a Jewish nursing home: building trust and enhancing personal control. Clin Gerontol 1994; 14(13): 99-117.

30. Levine J. Working with victims of persecution: lessons from Holocaust survivors. Soc Work 2001; 46(4): 350-360.

31. Verma S, Orengo CA, Maxwell R, et al. Contribution of PTSD/POW history to behavioral disturbances in dementia. Int J Geriatr Psychiatry 2001; 16(4): 356-360.

32. Shmotkin D, Blumstein T and Modan B. Tracing long-term effects of early trauma: a broad-scope view of Holocaust survivors in late life. J Consult Clin Psychol 2003; 71(2): 223-234.

33. Barak Y and Szor H. Lifelong posttraumatic stress disorder: evidence from aging Holocaust survivors. Dialog Clin Neurosci 2000; 2(1): 57-62.

34. Lomranz J. Amplified comment: the triangular relationships between the Holocaust, aging, and narrative gerontology. Int J Aging Hum Dev 2005; 60(3): 255-267.

35. Hirst SP, Le Navenec CL and Aldiabat K. Conversations with Holocaust survivor residents. J Gerontol Nurs 2011; 37(3): 36-42.

36. Teshuva $\mathrm{K}$ and Wells Y. Experiences of ageing and aged care in Australia of older survivors of genocide. Age Soc 2014; 34(3): 518-537.

37. UN Office on Genocide Prevention and the Responsibility to Protect. http://www.un.org/en/genocideprevention/ genocide.html, 2018

38. David P and Pelly S. Caring for aging Holocaust survivors: a practice manual. Toronto, ON, Canada: Baycrest Centre for Geriatric Care, 2004.

39. Zilberfein F and Eskin V. Helping Holocaust survivors with the impact of illness and hospitalization: social work role. Soc Work Health Care 1992; 18(1): 59-70.

40. Hirschfeld MJ. Care of the aging Holocaust survivor. Am J Nurs 1977; 77(7): 1187-1189.

41. Carstairs L. Culturally sensitive care for elderly Holocaust survivors. If Not Now E-J 2004; 5: 3.

42. Sandelowski M and Given LM. The SAGE encyclopedia of qualitative research methods. Thousand Oaks, CA: Sage, 2008.

43. Kripendorff K. Content analysis. An introduction to its methodology. London: Sage, 2013.

44. Graneheim UH and Lundman B. Qualitative content analysis in nursing research: concepts, procedures and measures to achieve trustworthiness. Nurse Educ Today 2004; 24(2): 105-112.

45. Kitwood T. The experience of dementia. J Aging Ment Health 1997; 1(1): 13-22.

46. McCormack L, Tillock K and Walmsley BD. Holding on while letting go: trauma and growth on the pathway of dementia care in families. Aging Ment Health 2017; 21(6): 658-667.

47. Scharf M and Mayseless O. Disorganizing experiences in second- and third-generation Holocaust survivors. Qual Health Res 2011; 21(11): 1539-1553.

48. Samson T, Shvartzman P and Biderman A. Palliative care among second-generation Holocaust survivors: communication barriers. J Pain Symptom Manage 2013; 45(4): 798-802.

49. Teshuva K, Borowski A and Wells Y. The lived experience of providing care and support services for Holocaust survivors in Australia. Qual Health Res 2017; 27(7): 1104-1114.: 10.1177/1049732316667702

50. Teshuva K and Wells Y. Aged care managers' perceptions of staff preparedness for caring for older survivors of genocide and mass trauma in Australia: how prepared are aged care workers. Australas J Ageing 2017; 36(1): E20-E22.

51. Kahana E, Kahana B and Riley K. Psychological perspectives of helplessness and control in the elderly (ed. PS Fry). Oxford: North Holland, 1989, pp. 121-153.

52. Burshnic VL, Douglas NF and Barker RM. Employee attitudes towards aggression in persons with dementia: readiness for wider adoption of person-centered frameworks. J Psychiatr Ment Health Nurs 2018; 25(3): 176-187. 
53. Woods B, Spector A, Jones C, et al. Reminiscence therapy for dementia: review. Cochrane Database Syst Rev 2005; 2: CD001120.

54. Swall A. Being in the present - the meaning of the interaction between older persons with Alzheimer's disease and a therapy dog. Solna: Karolinska Institutet, 2015.

55. Skovdahl K, Sörlie V, Kihlgren M, et al. Tactile stimulation associated with nursing care to individuals with dementia showing aggressive or restless tendencies: an intervention study in dementia care. Int J Older People Nurs 2007; 2(3): 162-170.

56. Hammar LM, Emami A, Engstrom G, et al. Communicating through caregiver singing during morning care situations in dementia care. Scand J Caring Sci 2011;25(1): 160-168.

57. Hedman R. Striving to be able and included. Solna: Karolinska Institutet, 2014.

58. Favaro A, Rodella FC and Santonastaso P. Binge eating and eating attitudes among Nazi concentration camp survivors. Psychol Med 2000; 30(2): 463-466.

59. Sindler AJ, Wellman NS and Stier OB. Holocaust survivors report long-term effects on attitudes toward food. J Nutr Educ Behav 2004; 36(4): 189-196.

60. Lincoln YS and Guba EG. Naturalistic inquiry. Newbury Park, CA: Sage, 1985. 